\title{
Remote Regioselective Electrophilic Aromatic Substitutions Using a Tetrafluoropyridyl (TFP) Phenol Protecting Group
}

\author{
William D. G. Brittain, ${ }^{*[a]}$ and Steven L. Cobb $*[a]$ \\ aDepartment of Chemistry, Durham University, South Road, Durham, DH1 3LE, United Kingdom
}

\begin{abstract}
Herein, we report the development of remote regioselective electrophilic aromatic substitution reactions enabled by the tetrafluoropyridyl (TFP) protecting group. The TFP group significantly reduces the reactivity of the aromatic ring to which it is attached allowing for substitution selectivity on non-TFP protected rings and in turn access to unsymmetric multi-aryl systems. Yields of the unsymmetric multi-aryl systems ranged between $58-96 \%$. In addition, we disclose that through sequential reactions and protection/deprotection of the TFP group, substitution patterns which do not conform to classical regioselectivity rules can be readily accessed.
\end{abstract}

\section{Introduction}

Despite the fact that there has been an increase in the number of reported "protecting group free" syntheses of natural products, ${ }^{[1]}$ and other complex organic molecules the fact remains that in the majority of cases the use of protecting groups is still required. While the primary role of a protecting group in complex organic synthetic pathways is to mask the reactivity of a particular functional group they are often utilised to also control chemical reactivity and / or reaction stereoselectivity. For example, nitrogen containing protecting groups such as amidines and imines are used in $\mathrm{C}-\mathrm{H}$ activation reactions, ${ }^{[2]}$ and groups such as TBDPS have been employed to add steric bulky to modulate the reactivity of adjacent function groups. ${ }^{[3]}$ In all of the aforementioned associated synthetic transformations the protecting group effect is localised and the subsequent reductions, additions, couplings occur near to or adjacent to the protecting group. Conversely reports of protecting groups being able to direct distal from their position have not been widely disclosed. ${ }^{[4]}$ In fact, in order to carry out these types of transformations bespoke directing groups often need to be installed into desired substrates and they subsequently remain within the products. ${ }^{[5]}$ Having the ability to use a 
protecting group to influence remote regiocontrol would offer an alternative approach to direct latestage functionalisation methods that typically rely on selective activation of the site of the reaction. ${ }^{[6]}$

a) Our Previous Work

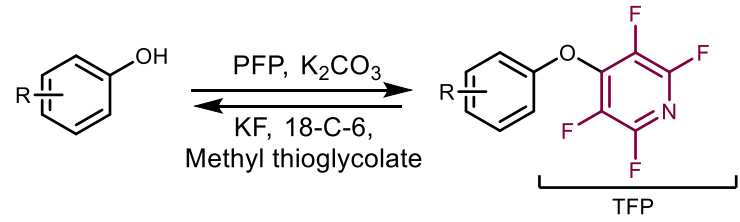

Introduction of the tetrafluoropyridyl protecting group for phenols

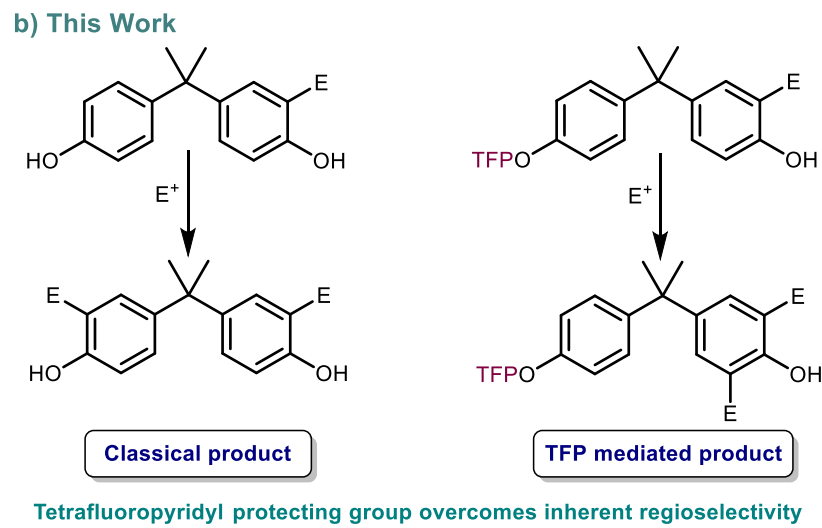

Scheme 1. a) Our previous work on the utilisation of TFP moieties as protecting groups for phenols. $b$ )

This work, the selective electrophilic aromatic substitution of multi-aromatic systems.

As part of a program of work in our laboratory to develop new multi-functional protecting groups we recently reported the use of the tetrafluoropyridyl (TFP) group for the protection of phenols (Scheme 1a). ${ }^{[7]}$ It was found that the TFP protecting group could be readily installed and cleaved from a range of phenol containing compounds. The TFP group was also found to be stable to a wide range of commonly employed reaction conditions. Unlike most of the alternatives the TFP group has somewhat of a unique position as being a phenol protecting group which is highly electron deficient. ${ }^{[8]}$ Due to this we envisaged that the TFP group could be used to modulate the reactivity profile of the phenolic ring it is attached to. In doing so the TFP protected phenol would be less reactive in electrophilic substitution reactions compared with either free phenols, alkyl ether protected phenols or even nonphenolic rings. If this was indeed the case, the reactivity difference afforded by TFP protection would 
provide a straightforward route to differentiate and regioselectively modify a specific ring in systems where multiple aromatic rings are present (Scheme 1b).

Herein, we detail our investigations into how tetrafluoropyridyl aryl ethers (TFP-ethers) can enable remote regioselectivity in electrophilic aromatic substitutions. The study demonstrates that TFPethers can be utilised to allow for efficient access to unsymmetrical biphenols, bisphenols and biaryls. The methodology reported overcomes the statistical product distribution which is a common drawback of the typical approaches used to access such compounds (e.g. cross-coupling). ${ }^{[9]}$

\section{Results and Discussion}

To begin the study, the electrophilic iodination of TFP-aryl-ether 1 was carried out under a range of conditions. ${ }^{[10]}$ Conversion of these reactions was studied using ${ }^{1} \mathrm{H}$ NMR spectroscopy (see ESI, S-31) and subsequently the best reactions were isolated to give solely the para-iodo regioisomer. To compare, the iodination of anisole $\mathbf{2}$ was carried out under the same conditions. From this comparative study it was observed that the TFP ether $\mathbf{1}$ was significantly less reactive than its methyl ether counterpart $\mathbf{2}$ across all of the conditions employed. For example, in the presence of silver sulfate and iodine (Table 1, Entries 1 and 5) the TFP ether 1 had only reached a conversion of 31\% after two hours, while anisole $\mathbf{2}$ had been completely consumed to give the iodinated product in the same time period. In order to rationalise these observations computational electron density distribution calculations were carried out (see ESI, S-197). This study showed that the positions which would typically undergo electrophilic aromatic substitution (ortho/para) were less electron-rich in the TFP phenol compared to the anisole, supporting the initial hypothesis and rationalising why a difference in reaction rate was observed.

To probe the substrate scope for iodination, a comparative study between a range of substituted TFPphenols and methyl-protected phenols was undertaken. We selected methyl- substituted compounds $\mathbf{1 b}$-d to study the regioselectivity of the reactions. These substrates were accessible to us as we had previously reported their synthesis. ${ }^{[7]}$ To investigate the differences in reactivity between the various 
substrates, two sets of reaction conditions were chosen, one in which both OTFP and OMe compounds reacted rapidly (NIS, TFA, rt, $1 \mathrm{~h}$ ) and one in which the OTFP was significantly less reactive than OMe $\left(\mathrm{AgSO}_{4}, \mathrm{I}_{2}, \mathrm{MeOH}, 50^{\circ} \mathrm{C}, 2 \mathrm{~h}\right)$. As with the previous study, conversion of the reactions was measured using ${ }^{1} \mathrm{H}$ NMR spectroscopy and the best reactions were isolated to determine the product regiochemistry (see ESI, S-42-S-85).

Table 1. lodination condition screening for anisoles and TFP aryl ethers

\begin{tabular}{|c|c|c|c|c|}
\hline & & $\begin{array}{l}\operatorname{TFP} 1 \mathbf{1 a} \\
\operatorname{Me} 2 \mathbf{a}\end{array}$ & & \\
\hline Entry & & Conditions & $\begin{array}{l}\text { Conv } \\
(\%)^{a}\end{array}$ & Yield $(\%)^{b}$ \\
\hline 1 & $1 a$ & $\begin{array}{l}\mathrm{AgSO}_{4}(1.2 \text { equiv. }), l_{2}(1.2 \text { equiv. }) \\
\mathrm{MeOH}, 50^{\circ} \mathrm{C}, 2 \mathrm{~h}\end{array}$ & 31 & - \\
\hline 2 & 1a & NIS (1.1 equiv.), TFA, rt, $1 \mathrm{~h}$ & 94 & 80 \\
\hline 3 & 1a & $\begin{array}{l}\text { NIS ( } 1.1 \text { equiv.), TFA ( } 0.3 \text { equiv.), } \\
\text { MeCN, rt, } 1 \mathrm{~h}\end{array}$ & $<1$ & - \\
\hline 4 & 1a & $\mathrm{NIS}$ (1.1. equiv), $\mathrm{CF}_{3} \mathrm{SO}_{3} \mathrm{H}, \mathrm{rt}, 1 \mathrm{~h}$ & 87 & - \\
\hline 5 & 2a & $\begin{array}{l}\mathrm{AgSO}_{4}\left(1.2 \text { equiv.), } \mathrm{I}_{2} \text { (1.2 equiv.), }\right. \\
\mathrm{MeOH}, 50^{\circ} \mathrm{C}, 2 \mathrm{~h}\end{array}$ & $>99$ & 98 \\
\hline 6 & $2 a$ & NIS (1.1 equiv.), TFA, rt, $1 \mathrm{~h}$ & $>99$ & 96 \\
\hline 7 & $2 a$ & $\begin{array}{l}\text { NIS ( } 1.1 \text { equiv.), TFA ( } 0.3 \text { equiv.), } \\
\text { MeCN, rt, } 1 \mathrm{~h}\end{array}$ & 68 & - \\
\hline 8 & $2 a$ & $\mathrm{NIS}$ (1.1. equiv), $\mathrm{CF}_{3} \mathrm{SO}_{3} \mathrm{H}, \mathrm{rt}, 1 \mathrm{~h}^{\mathrm{c}}$ & - & - \\
\hline \multicolumn{5}{|c|}{$\begin{array}{l}\text { a) conversion determined by inspection of }{ }^{1} \mathrm{H} \text { NMR spectra b) yield } \\
\text { following purification by column chromatography c) a mixture of } \\
\text { regioisomeric products was observed, therefore, conversion was not } \\
\text { determined }\end{array}$} \\
\hline
\end{tabular}

Across the series, it was observed that under silver sulfate-mediated conditions all OMe derivatives (2b-f) were significantly more reactive than their OTFP (1b-f) counterparts. For example, in the cases of 4-methyl compounds $\mathbf{1} \mathbf{d}$ and $\mathbf{2} \mathbf{d}$ where complete quantitative conversion to the iodo compound was seen for the OMe derivative (2d) no conversion was obtained for the OTFP compound (1d) (Table 2, Entries 3 and 8). It was observed from the isolated compounds that the regiochemical outcomes were consistent between OTFP and OMe compounds, which was expected from the previously calculated electron density distribution profiles (see ESI, S-197). 
Table 2. Comparison of reactivity and regioselectivity between substituted OMe-and OTFP-containing compounds

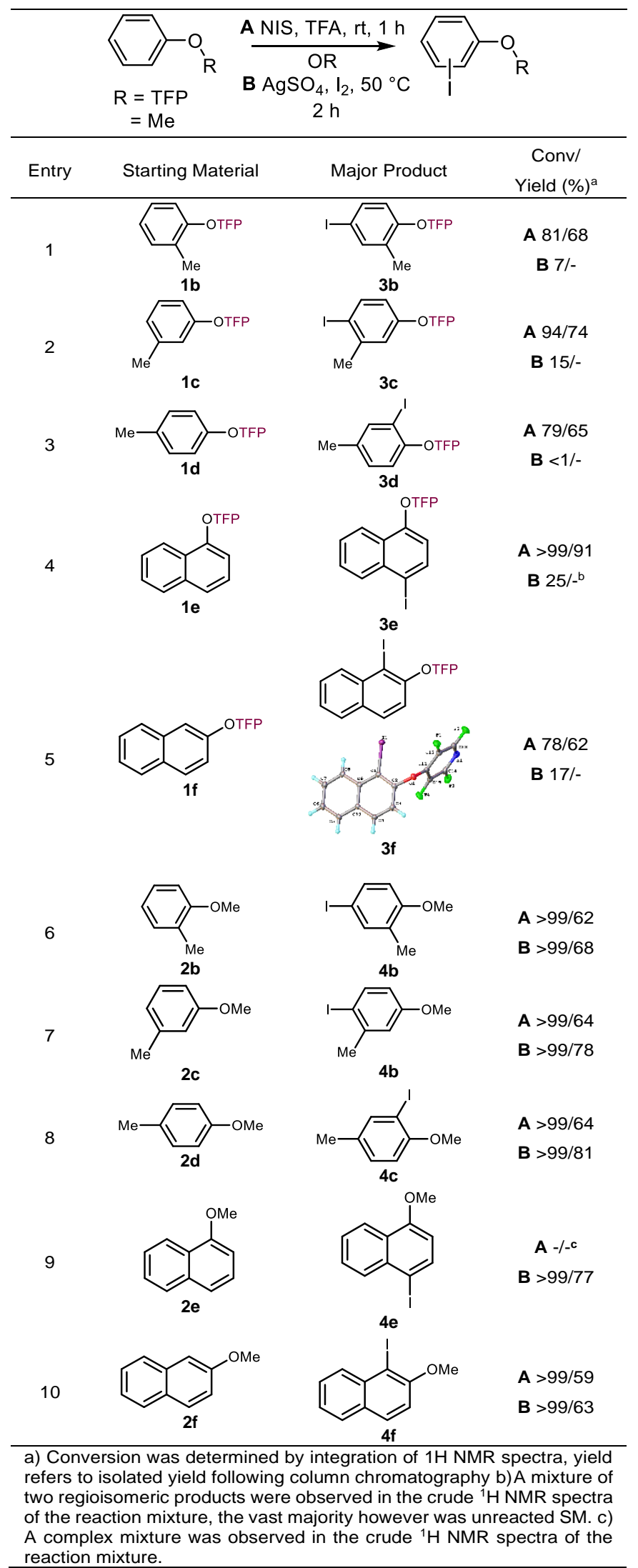


After it had been confirmed that a range of TFP-protected phenols could undergo iodination, a competition experiment utilising a compound containing two phenol rings, one protected with a TFP group and one with a methylated phenolic oxygen, was undertaken. The orthogonally protected biphenol $\mathbf{5 a}$ was synthesized in one step (see ESI, S-17). 5a was then exposed to iodination conditions (TFA, NIS, rt, 1h), which were shown to readily iodinate both OMe and OTFP substrates. From the ${ }^{1} \mathrm{H}$ NMR spectrum obtained it was clear that mono-substitution had occurred and that one regioisomer (>95\%) was formed (Table 3, Entry 1 ). This compound was purified and its regiochemistry confirmed by $2 \mathrm{D}$ NMR (see ESI, S-113-S-116). As hypothesised the substitution only occurred on one of the aromatic rings and ortho to the methoxy group (Table 3, Entry 1). This demonstrated that even under conditions in which both OTFP and OMe aryl rings could undergo electrophilic aromatic substitution, the reaction occurred selectively only on the OMe-substituted ring. When the OTFP group was moved to the meta position relative to the central C-C biaryl bond (5b) iodination still occurred selectively only on the OMe-substituted ring (6b) (Table 3, Entry 2). In a competition experiment between an OTFP-protected phenol ring and a free phenolic ring it was found that only substitution occurred on the free phenolic ring. Substitution occurred ortho to the oxygen in the case of compound $\mathbf{5 c}$ and para to the oxygen in compound $\mathbf{5 d}$ (Table 3 , Entries 3 and 4). We also wished to study iodination of bisphenols, where the two phenolic rings are not directly attached to each other. This is an important class of compounds, especially in the polymer arena (such as bis-phenol A (BPA)). ${ }^{[11]}$ A series of bisphenol TFP derivatives were synthesised (5e-g) and subsequently iodinated to give the monoiodinated products. As previously seen for the biphenol systems regioselective substitution adjacent to the phenolic oxygen was observed to give $6 \mathrm{e}-\mathrm{g}$. The structures of $6 \mathrm{e}-\mathrm{g}$ were confirmed by 2D NMR correlations (Table 3, Entries 5-7) (see ESI, S-138-S-156). It is worth noting that when unprotected BPA was exposed to the same iodination reaction conditions (NIS, TFA, rt) an inseparable mixture of mono- and di-iodinated products in addition to unfunctionalised BPA was generated (see ESI, S-195 S-196). We were also able to selectively modify a TFP-protected BINOL (5h) to regioselectively generate $6 \mathbf{h}$ (Table 3, Entry 8). Finally, we wished to test the reactivity difference between a TFP- 
phenolic ring and an unmodified phenyl ring. Substrate $\mathbf{5 i}$ was synthesised in one step from 4phenylphenol as previously reported. ${ }^{[7]}$ Iodination of $\mathbf{5 i}$ resulted in the regioselective formation of compound $\mathbf{6} \mathbf{i}$ in $87 \%$ yield (Table 3, Entry 9). $\mathbf{6} \mathbf{i}$ would not be expected regio-isomer if the iodination reaction was carried out in the absence of the TFP protecting group. Here the reactivity of the system would be the inverse, and iodation would be expected to occur on the more activated phenolic ring.

Table 3. Scope of selective iodination reaction

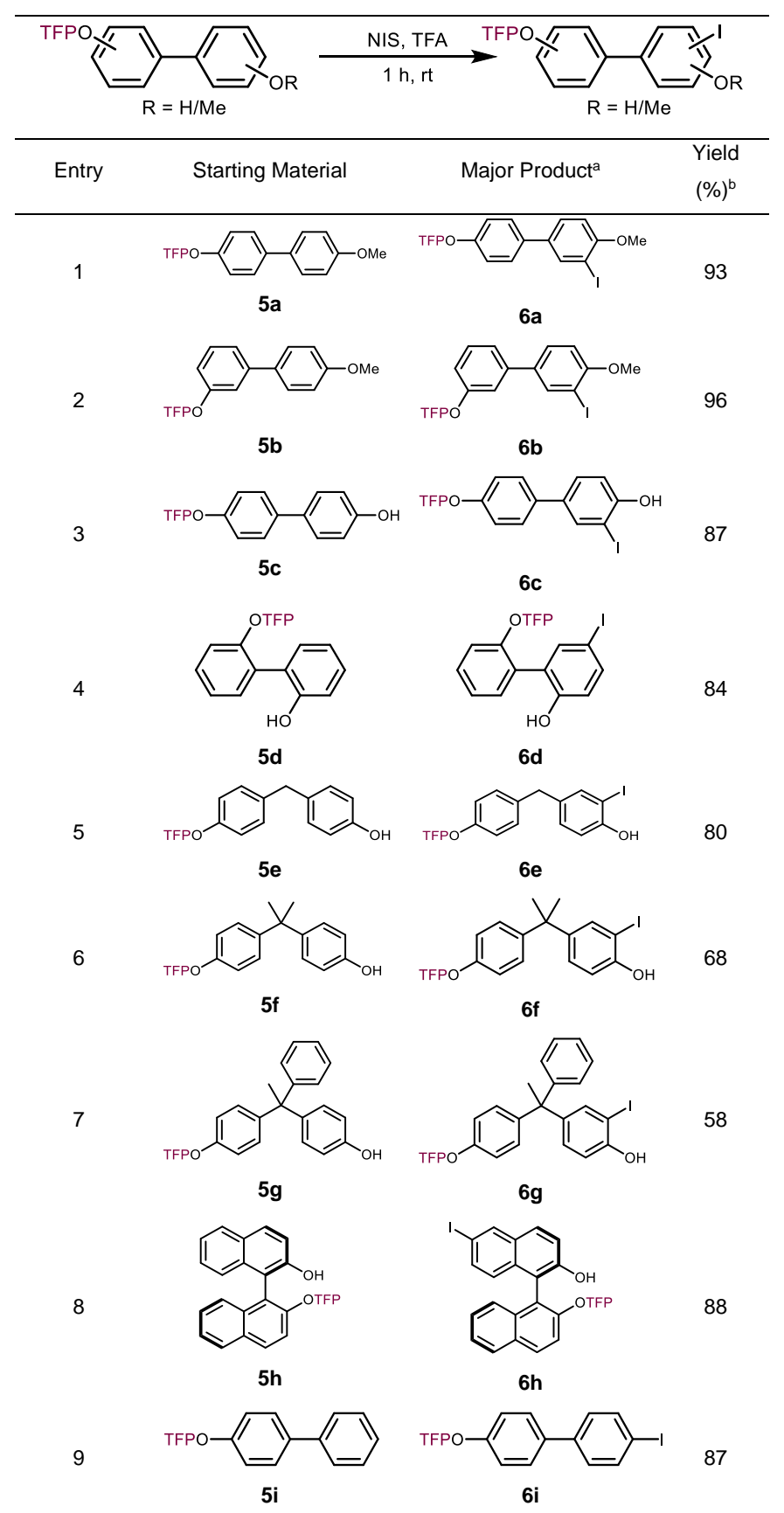

a) Regiochemistry of product determined by 2D NMR analysis. b) isolated yield following flash column chromatography. 
Having established the ability of the TFP group to clearly control the regioselectivity of electrophilic substitution reactions we wished to test if the methodology could be utilised to add further electrophiles regioselectively to the aromatic ring of our choice. To test this idea, a second iodination reaction under the previously employed conditions was carried out on compound $\mathbf{6 f}$. The second iodine was added selectively onto the same ring as the first, ortho to the free phenolic oxygen, giving di-iodo compound $\mathbf{8}$ in $57 \%$ yield (Scheme 2). The regiochemistry of 8 was confirmed by obtaining a crystal structure ${ }^{[12]}$ and further evidenced by 2D NMR spectra (see ESI, S-176 - S-181). This result showed that even a ring which had already been substituted with a deactivating iodine group was still more reactive than the TFP-protected phenol ring. This is the first example, to the best of our knowledge of the synthesis of an unsymmetrical bisphenol system in which two electrophiles have been added selectively to only one aromatic ring. By removal of the TFP group from compound $\mathbf{5} \mathbf{f}$ and then subsequent iodination, ${ }^{[7]}$ we could selectively install a single iodine on to each of the aromatic rings giving 10 in $\mathbf{7 3 \%}$ yield (Scheme 2). The synthesis of $\mathbf{8}$ and $\mathbf{1 0}$ clearly demonstrated that the TFP protecting group allows for the precise regiocontrol of electrophilic aromatic substitution reactions even those occurring remotely.

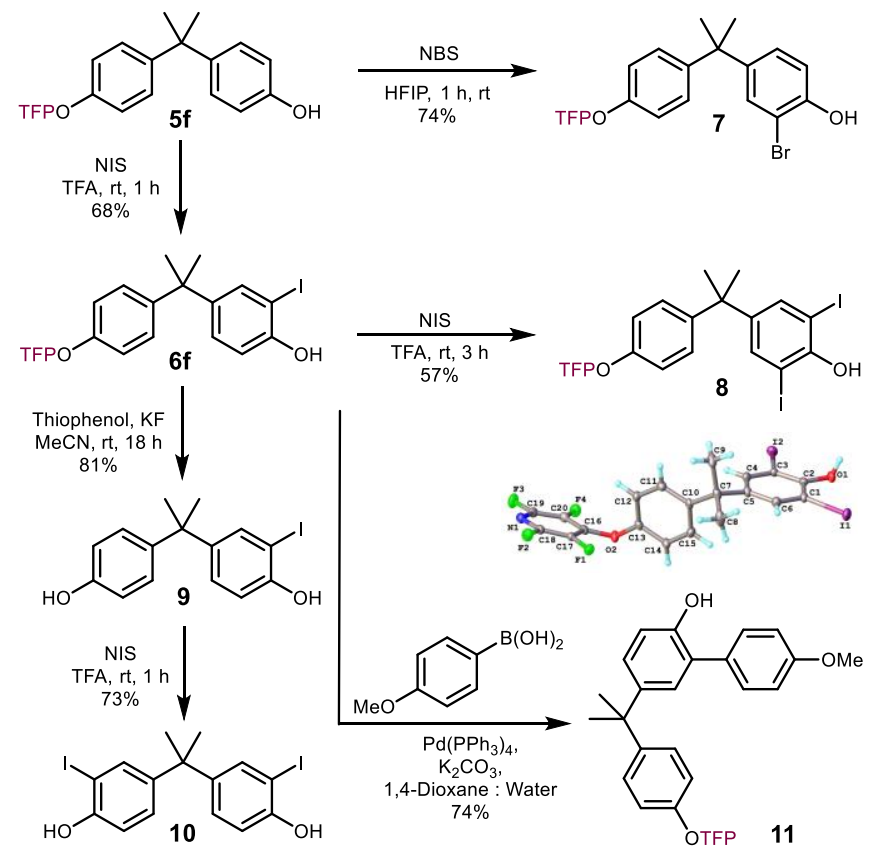

Scheme 2. Further synthetic modifications. 
The synthesised aryl species, $\mathbf{5} \mathbf{f}$ and $\mathbf{6 f}$ were further modified (Scheme 2). By exposing the mono-iodoTFP-bisphenol A derivative $\mathbf{6 f}$ to Suzuki-Miyaura cross-coupling conditions, the tri-aryl compound 11, with one free phenolic oxygen and two orthogonally protected phenolic oxygens, was produced in 74\% yield (Scheme 2). The TFP group could be easily removed from compound $\mathbf{5} \mathbf{f}$ using a modified version of our previously reported conditions ${ }^{[7]}$ to give mono-iodo-bisphenol A 9 in $81 \%$ yield (Scheme 2). Other electrophiles could also be employed, for example, bromination of compound $\mathbf{5} \mathbf{f}$ occurred smoothly to give a single regioisomeric product 7 in $74 \%$ yield (Scheme 2), consistent with the regioselecitivity observed for iodination.

\section{Conclusion}

In conclusion, we have demonstrated that through installation of a tetrafluoropyridyl (TFP) moiety on a phenolic ring, the aromatic system's propensity to engage in electrophilic aromatic substitution can be significantly reduced. The methodology reported allows for precise and remote regiocontrol of substitution reactions without the requirement for a bespoke directing group. We have demonstrated that the TFP group can perform dual functions, acting as both a protecting and a directing group. Given this, through sequential reactions and protection/deprotection of the TFP group, substitution patterns within aromatic systems which do not conform to classical regioselectivity rules can be readily accessed.

\section{Acknowledgements}

SLC and WDGB would like to acknowledge the Biotechnology and Biological Sciences Research Council [BB/P003656/1] and Durham University's Medical Research Council Confidence in Concept scheme for financial support [MC-PC-17157]. Dr Mark Fox is thanked for carrying out computational calculations. Dr Juan A. Aguilar and Catherine Heffernan are thanked for NMR spectroscopy support. Dr Dmitry S. Yufit is thanked for help in the collection of X-ray crystal data and solving of the reported crystal structure. 


\section{References}

[1] a) I. S. Young, P. S. Baran, Nature Chemistry 2009, 1, 193-205; b) P. S. Baran, T. J. Maimone, J. M. Richter, Nature 2007, 446, 404; c) L. P. Martinez, S. Umemiya, S. E. Wengryniuk, P. S. Baran, J. Am. Chem. Soc 2016, 138, 7536-7539; d) C. Hui, F. Chen, F. Pu, J. Xu, Nature Reviews Chemistry 2019, 3, 85-107.

[2] a) S. J. Pastine, D. V. Gribkov, D. Sames, J. Am. Chem. Soc 2006, 128, 14220-14221; b) C. Sambiagio, D. Schönbauer, R. Blieck, T. Dao-Huy, G. Pototschnig, P. Schaaf, T. Wiesinger, M. F. Zia, J. Wencel-Delord, T. Besset, B. U. W. Maes, M. Schnürch, Chem. Soc. Rev. 2018, 47, 66036743; c) R.-Y. Zhu, M. E. Farmer, Y.-Q. Chen, J.-Q. Yu, Angew. Chem. Int. Ed. 2016, 55, 1057810599; d) D. J. Abrams, P. A. Provencher, E. J. Sorensen, Chem. Soc. Rev. 2018, 47, 8925-8967.

[3] M. Bols, C. M. Pedersen, Beilstein J. Org. Chem. 2017, 13, 93-105.

[4] a) W. A. Golding, R. Pearce-Higgins, R. J. Phipps, J. Am. Chem. Soc 2018, 140, 13570-13574; b) H. J. Davis, G. R. Genov, R. J. Phipps, Angew. Chem. Int. Ed. 2017, 56, 13351-13355.

[5] a) M. T. Mihai, H. J. Davis, G. R. Genov, R. J. Phipps, ACS Catal. 2018, 8, 3764-3769; b) B. Lee, M. T. Mihai, V. Stojalnikova, R. J. Phipps, J. Org. Chem. 2019; c) Z. Liu, X. Li, T. Zeng, K. M. Engle, ACS Catal. 2019, 9, 3260-3265; d) S. K. Nimmagadda, M. Liu, M. K. Karunananda, D.-W. Gao, O. Apolinar, J. S. Chen, P. Liu, K. M. Engle, Angew. Chem. Int. Ed. 2019, 58, 3923-3927.

[6] a) T. Cernak, K. D. Dykstra, S. Tyagarajan, P. Vachal, S. W. Krska, Chem. Soc. Rev. 2016, 45, 546576; b) D. A. DiRocco, K. Dykstra, S. Krska, P. Vachal, D. V. Conway, M. Tudge, Angew. Chem. Int. Ed. 2014, 53, 4802-4806; c) M. Leroux, T. Vorherr, I. Lewis, M. Schaefer, G. Koch, K. Karaghiosoff, P. Knochel, Angew. Chem. Int. Ed. 2019, 58, 8231-8234.

[7] W. D. G. Brittain, S. L. Cobb, Org Biomol Chem 2019, 17, 2110-2115.

[8] a) A. S. Hudson, A. Hoose, C. R. Coxon, G. Sandford, S. L. Cobb, Tetrahedron Lett 2013, 54, 4865-4867; b) A. M. Webster, C. R. Coxon, A. M. Kenwright, G. Sandford, S. L. Cobb, Tetrahedron 2014, 70, 4661-4667.

[9] P. Zhao, M. D. Young, C. M. Beaudry, Org. Biomol. Chem 2015, 13, 6162-6165.

[10] a) M. Bergström, G. Suresh, V. R. Naidu, C. R. Unelius, Eur J Org Chem 2017, 2017, 3234-3239; b) A. M. Steer, H. L. Bolt, W. D. G. Brittain, S. L. Cobb, Tetrahedron Lett 2018, 59, 2644-2646; c) M. C. Carreño, J. García Ruano, G. Sanz, M. A. Toledo, A. Urbano, Tetrahedron Lett 1996, 37, 4081-4084; d) A.-S. Castanet, F. Colobert, P.-E. Broutin, Tetrahedron Lett 2002, 43, 5047-5048.

[11] a) K. Endo, T. Yamade, Polymer Journal 2008, 40, 212-216; b) H. Uyama, N. Maruichi, H. Tonami, S. Kobayashi, Biomacromolecules 2002, 3, 187-193; c) A. M. Nelson, T. E. Long, Polymer International 2012, 61, 1485-1491.

[12] CCDC 1947954 and 1948713 contains the supplementary crystallographic data for this paper. These data are provided free of charge by The Cambridge Crystallographic Data Centre. 